\title{
One way to communicate the value of Enterprise Architecture - maturity levels for IT applications
}

\author{
Karoline Westerlund ${ }^{1}$ \\ 1Umeå universitet, SE-901 87 Umeå, Sweden, karoline.westerlund@umu.se
}

Keywords

Governance, Enterprise Architecture, Life Cycle Management, Health Check Model, BCG matrix.

\section{ABSTRACT}

IT Office is accountable for creating value of IT investments and is responsible for reporting the value of the IT application portfolio. The University Management has given the IT Office a mandate to have the strategic responsibility for all the common IT at the university, applications and technology. Among other things the IT Office is supposed to contribute with information over the status of all IT systems, investment plans involving IT and the annual cost for IT in the university's annual report. This information is also an important input to our corporate strategy for IT and to IT related decisions on maximizing value of investments.

We needed information and control. As a first step, we built an enterprise architecture (EA) framework and set up a repository where all the information is stored to help us to take control over our IT applications and technical infrastructure. As a result we now have useful information about the objects we have. But the object map is very static and does not say anything about the systems life cycle and level of maturity. Now it was time to obtain more information about each system's status. We were ready to take the next step and penetrate in to each application.

I wanted to develop a life cycle management model and use it as one way to communicate the value of EA and the value each application delivers to the end-users. From my point of view, the goal was to describe maturity levels for each application in a line graph and present the output in an overall view that was easy for the senior management and end-users to understand. In the line graph I wanted to follow all the applications from when they left the project phase until they were phased out, or as it sometimes turned out, re-born. I wanted to show the trends and point out the applications that belonged to the area that gave good return of investment. There were questions that needed answers; should we invest in the system, for what purpose, or phase out? I needed a method and decided to try to work with the BCG matrix as one input. Other inputs we already had was our Health Check Model and the goals in the maintenance plan for each object family.

We had developed a Health Check Model to use as one input to ensure that the applications were maintained effectively and to help identifying candidates for retirement. We created a survey with questions to give a picture over a system's health status based on the business value the system provides and its technical quality. It is a self-evaluation form, a subjective view from our system owners, and the results are compiled in a matrix.

Influenced by the BCG matrix I tried to develop our version. The focus was to take a position on the applications based on a number of factors. I identified seven areas of interest to consider; technology, functionality, support, costs, users, reliability and supplier. For each area I used different adjectives to describe the qualities for each system. I wanted the EA team to start life cycle thinking, introduced the model to the group, did some brainstorming, and asked them to try to use it. It took some discussion to get a helicopter view but finally we had our applications mapped in the matrix.

In the line graph I put development as a parameter on the $y$-axis and change over time on the $x$-axis. I divided the $\mathrm{x}$-axis into five stages that a system could be in; Introduction, Growth, Maturity, Decline or Settled. With the results in mind from the other steps the EA team plotted out the applications they were responsible for in the graph. Together, we discussed the results and set the picture. The result turned out to be a bestseller. The management and employees became very interested in the picture. We do our homework once a year when it's time for the annual report and 
the picture freezes for the next year. The yearly status is compared with the previous year and helps to identify which systems seem to need to be addressed.

In the oral presentation I will show one way to communicate the value of EA. I will present the life cycle line graph over our IT applications and discuss what conclusions and decisions we have taken to get there. As a result of this session, participants will be able to relate to the life cycle management model that we use to describe maturity levels for our IT applications and reporting the value of our application portfolio.

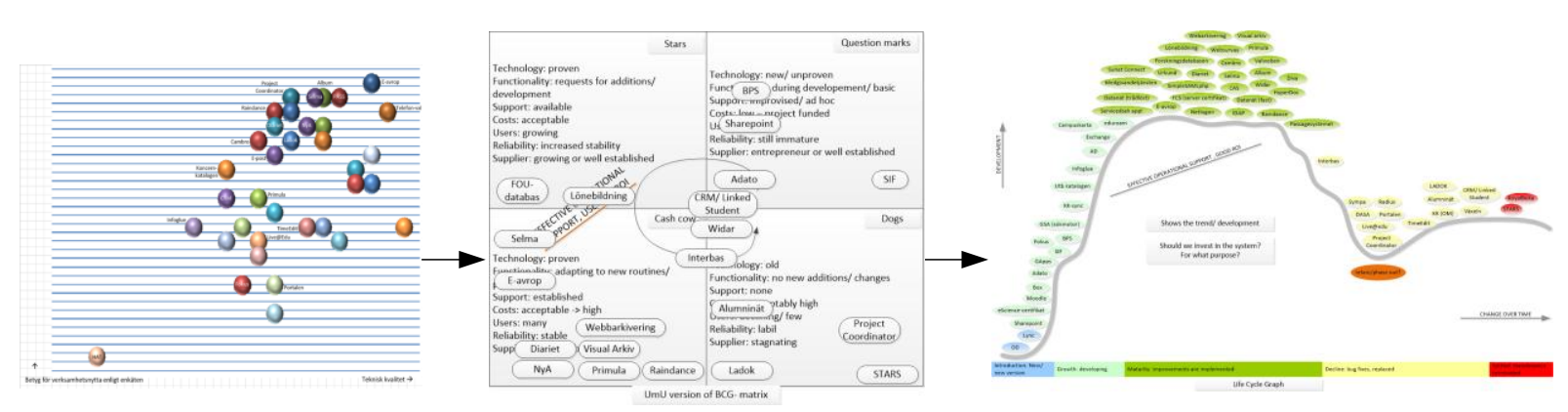

Figure 1. From Health Check Model via BCG matrix to Life Cycle Analysis EA Object map

\section{REFERENCES}

Westerlund, K (2012) How we built an Enterprise Architecture framework meeting our needs, EUNIS (2012), www.eunis.pt/images/docs/abstacts/P2C1.pdf

Westerlund, K (2011) On Budget is Not Enough - Lesson Learned Leaving an Email System from the 90s, EUNIS (2011), www.eunis.ie/papers/On-Budget-Is-Not-Enough_KarolineWesterlund_Paper.pdf

\section{AUTHORS' BIOGRAPHIES}

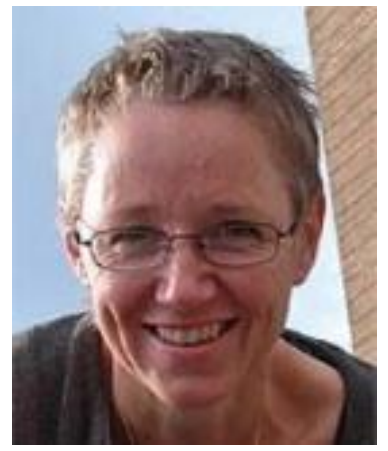

K. Westerlund. I work as an IT-strategist at Umeå University since 1997. I am a part of the IT-Office and we have a mandate from the University Management to take strategic responsibility for all common IT at the university. Between the years 1994 to 1997 I worked as a project manager and was responsible for the development of an IT system supporting human recourses, named Primula, for higher education in Sweden. At the beginning of the $90 \mathrm{~s}$ I worked as a development strategist at Umeå University and in the sector. During the years 2006 to 2012 I was a member of the Ladok Board. Ladok is a national system for study administration within higher education in Sweden owned by a consortium. I have studied informatics, economics and law at Umeå University. 